\title{
A General Analytical Model for Problem Solving Teaching: BoS ${ }^{*}$
}

\author{
Ali Kürşat Erümit ${ }^{a}$, Vasif Nabiyev ${ }^{b}$, Temel Kösa ${ }^{c}$, Mehmet Kokoç ${ }^{d}$, Ayşegül Aksoy \\ Gencan $^{\text {e }}$
}

${ }^{a}$ Trabzon University, Fatih Faculty of Education, Trabzon/Turkey (ORCID: 0000-0003-4910-4989)

${ }^{\mathrm{b}}$ Karadeniz Technical University, Faculty of Engineering, Trabzon/Turkey (ORCID: 0000-0003-0314-8134)

${ }^{c}$ Trabzon University, Fatih Faculty of Education, (ORCID: 0000-0002-4302-1018)

${ }^{\mathrm{d}}$ Trabzon University, Fatih Faculty of Education, (ORCID: 0000-0002-1347-8033)

${ }^{\mathrm{e}}$ Trabzon University, Fatih Faculty of Education, (ORCID: 0000-0002-1341-8823)

Article History: Received: 21 November 2018; Accepted: 3 March 2019; Published online: 14 March 2019

\begin{abstract}
In this study, a general analytical model called Bag of Solution (BOS) was developed to help students understand and solve mathematical problems. The model is based on graph theory, a topic under discrete mathematics. The types of problems to be modelled for BoS were determined by looking at densities of the problems in the central placement examinations and exam preparation books. As a result, three types of problems were selected; namely Mixture, Worker and Motion problems. In order to develop a common model for solution of the three types of problems, a total of 1509 mixture, worker and movement problems were examined. After the analysis, the problem types were taken together, and variable relations were determined, and a common graph model was created. Since it is an algorithmic model, it allows solving problems both by paper and pencil and computer. This study proves that different types of problems (with different scenarios, objects and object relations) can be solved using a single model. It is expected that the BoS developed in this study will offer two benefits. It is hoped to both provide an algorithmic basis for computer-aided instructional materials, adaptive systems and intelligent tutoring systems to be developed for problem solving and also help students to develop a new understanding of the problem-solving process. A common graph structure that can covers the entirety of a problem can allow students to construct their own learning while solving the problem step by step.
\end{abstract}

Keywords: Graph theory, problem modeling, problem solving, bag of solution

DOI: $10.16949 /$ turkbilmat.486084

\section{Introduction}

Problem solving is an important skill and cognitive process that affects both social and intellectual aspects of individuals and thus is defined by Popper (1999) as life itself (Jonassen, 2011). For this reason, it is also at the centre of mathematical thinking and learning in academic sense (De Corte \& Masui, 2004; English \& Gainsburg, 2016; Sweller, Clark, \& Kirschner, 2010). The fact that problem solving has an important place in mathematical success moved this issue into the focus of mathematics teaching program at many levels starting from primary education (Yavuz-Mumcu \& Baki, 2017). When examined, K-12 curricula of different countries such as Germany, France, USA, Japan and China are seen to place emphasis on development of learners' problem-solving skills. As a matter of fact, the National Council of Teachers of Mathematics (NCTM) standards also

*This research is supported by The Scientific and Technological Research Council of Turkey (Project Number: TÜBİTAK215K029)

Citation Information: Erümit, A. K., Nabiyev, V., Kösa, T., Kokoç, M. \& Aksoy-Gencan, A. (2019A General Analytical Model for Problem Solving Teaching: BoS. Turkish Journal of Computer and Mathematics Education, 10(2), $476-500$. 
indicate the prioritized need for increased problem solving success as part of mathematics teaching. This suggests that mathematics educators and researchers agree that problemsolving skills of students must be enhanced and it must be a primary objective of education (Cai, 2003).

Many studies in this scope demonstrated that although students do not have difficulty in exercises that require knowledge of four operations (addition, subtraction, multiplication and division), they experience difficulties in verbal problems requiring knowledge of both operations and concepts, and they make mistakes in problems that require more than one operation for solution (Anzelmo-Skelton, 2006; Gooding, 2009; Singh \& Lokotsch, 2005). Moreover, most studies reported that students face difficulties in understanding the concepts involved in problems and relations among those concepts while solving verbal problems (Ben-Hur, 2006; Chiu \& Klassen, 2010; Vicente, Orrantia \& Verschaffel, 2007).

These difficulties are accounted for by factors such as students cannot receive effective feedback in the traditional teaching environment, they can not create alternative solutions, they can not be motivated, they learn problem solving by memorizing formulas, and teachers cannot catch up with overcrowded classrooms (Blatchford, Bassett, \& Brown, 2011; Chingos, 2012; Cho, Glewwe \& Whitler, 2012; Thomas, 2012). According to Polya (1957), one of the most important reasons for these difficulties is the inability of students to perceive problem solving as a gradual process.

This implies that problem solving is a process in which cognitive skills are employed rather than a structure in which only arithmetic operations are performed. This view is also supported by many studies on problem solving processes and strategies (Crippen \& Earl, 2007; Hoffman \& Spatariu, 2008; Huang, Liu \& Chang, 2012; Yen \& Chen, 2008). Taking into account the mental skills used in the problem solving process, it is seen that this process includes understanding and bridging the information; critical, creative and reflective thinking; and analysis and synthesis skills (Soylu \& Soylu, 2006). This process can be carried out effectively if students' problem-solving skills are improved (De Corte \& Masui, 2004).

Polya (1957) proposed a 4-step model for problem-solving skills (understand the problem, devise a plan, carry out the plan, and look back). Polya also pointed out that problem solving is perceived as an operation of finding the correct result only (Polya, 1957); however, it is about finding a way for overcoming a difficulty as well as an action and conclusion that actually encompasses a broader mental process and skills.

Polya (1957) stressed that a real problem can be solved by simulating a simple problem, and general problem solving strategies can be created in this way. Similarly, about teaching of problem solving skills, the literature shows that it is important to study a large number of mathematical examples and thus understand the structure of the problem beyond merely memorizing template formulas (Sweller et al., 2010). However, relevant studies revealed that students' verbal problem solving skills are not at the targeted level and they are not able to adapt a strategy developed for solving a problem to new situations (Elia, van den Hauvel-Panhuizen \& Kolovou, 2009; Erdoğan, 2015). In other words, even 
if students succeed in developing a strategy for a type of problem, they can hardly generalize the strategy. This is due to the fact that students see the questions about verbal problems as discrete and therefore can not apply the strategies they had previously taken to solve the problem because mathematics curricula have different types of problems using different types of objects (e.g. number, fraction, mixture, motion, age, worker, etc.).

It can be considered that the students' grasping mathematical problems analytically and focusing on the solution independently on the scenario could contribute to development of problem solving skills. In order to be able to test this proposal, it is first necessary to examine in detail the types of problems handled under different scenarios and contexts and to model solutions of the related problems. At this point, it would be useful to examine the concepts of mathematical model and modeling.

Models and modeling perspectives on Mathematics teaching, learning, and problem solving were discussed earlier before as an important topic (Lesh \& Doerr, 2003). In that, Mathematical modeling is the process of mathematical description of anything in real life (Berry \& Houston, 1995). Working with mathematical models contributes to development of ideas that can be modelled for many new inventions (Skemp, 1986). In other words, working with models can contribute to development of different ideas in different areas as well as academic achievement. One of the most important benefits of modeling is that it helps students also to solve non-routine problems. For example, a student who solves problems with small numbers in a certain pattern can not solve the same type of problem given with slightly larger numbers. In this case, the necessity of modeling comes to the forefront (Olkun, Şahin, Akkurt, Dikkartin \& Gülbağc1, 2009). In the study conducted by Olkun et al. (2009), it was found out that some of the students could improve their ability to solve non-routine problems by experiencing the modeling process. In another survey on students' ability to transfer what they have learned in mathematics to everyday life, it was found out that the groups using mathematical modeling proved superior ability to transfer mathematics to everyday life compared to test groups (Doruk \& Umay, 2011). In a comprehensive study by Çelik and Güler (2013), it was found out students cannot solve real life problems. In order to overcome this situation, it was suggested to perform modeling activities with students besides arithmetic operations taught in routine problems. Similarly, Erdem, Doğan, Gürbüz and Şahin (2017), concluded that in order to use problem solving ability effectively in real life, firstly, modeling activities should be included in textbooks correctly and effectively. Blum (2011) found out that students are inclined to create a mathematical model that is unsuitable for solving the problem by adapting the previously known numeric values to the schematics they have previously learnt. In another study related to modeling, it was seen that the individuals who can understand and apply the concept of modeling recorded higher points (Dede, 2017). Relevant studies show that mathematical modeling plays a key role in improving problemsolving skills.

Various approaches to modeling the solutions of mathematical problems are known (Kaiser \& Schwarz, 2006). One of these approaches is to use graph theory for modeling of problem solutions. A graph is a structure defined with the help of edges that represent a 
set of points and the relationships between these points. For this reason, graph structures can be used to model the relationships between given values and required values in mathematical problems. All variables related to the type of problem as well as their relationships to each other are described. Therefore, the model generated by using the graph structure can depict possible different paths to solve the related mathematical problem and steps of the operation to follow for each path (Nabiyev, 2012).

One of the important benefits of graph theory is that it allows algorithmic expression of graphically constructed structures. So creating a graph specific to a type of problem also means that its algorithm has been created in order to program that type of problem by using a computer. Programming graphs allows transfer of the benefits gained on paper (i.e. seeing the variables related to the type of problem, the relationships among them, operations that can be done, different paths that can be followed for solution, and the ability to instantaneously detect strategic errors during the operation) (Nabiyev, 2012).

In studies conducted to increase problem solving success, the applications utilizing computer technologies besides many teaching methods also play an important role (Hoffman \& Spatariu, 2008; Huang et al., 2012; Li \& Ma, 2010; Yen \& Chen, 2008). In most of the studies in which computer technologies are used, students' willingness and enthusiasm about solving problems increased, and this encouraged them to develop positive attitudes in this regard (Garcia-Santillán, Flores-Zambada, Escalera-Chávez, Chong-González \& Lopez-Morales, 2012; Huang et al., 2012). In addition, it was found out that computer technologies bear the potential of promoting mathematics learning processes (Garcia-Santillán et al., 2012; Huang et al., 2012; Lopez-Morteo \& Lopez, 2007). Most of such studies demonstrated that students' academic success increased in relation with problem solving (Chang, Sung \& Lin, 2006; Garcia-Santillán et al., 2012; Huang et al., 2012; Li \& Ma, 2010).

For this reason, a common model for solving problems is considered important in teaching of mathematical problems with and without computer. In this way, a learning experience can be attained where process gains importance and analytic logic is taught through computers, and teaching based on templates through memorization of formulas can be abandoned by helping students assess problems analytically on a common ground and understand the logic of solution.

Departing from that, our study intends to model the general analyser (Bag of Solution $(\mathrm{BoS}))$ of motion, worker and mixture problems based on graph theory. In this framework, answer is sought for the research questions below;

a. What are the structural characteristics of motion, worker and mixture type problems?

b. Is it possible to combine motion, worker and mixture type problems under a common model $(B o S)$ ? 


\section{Modeling of the General Analyser (BoS)}

In this study, a general analytical model called Bag of Solution (BOS) was developed to help students understand and solve mathematical problems. The model is based on graph theory, a topic under discrete mathematics. The model allows solving problems in computer environment as well as by paper and pencil.

A graph is a structure defined with the help of edges that expresses a set of points (nodes) and the relationships between these points $\mathrm{G}=(\mathrm{Y}, \mathrm{E})$, and it can be expressed as a set of finite $\mathrm{V}$ and $\mathrm{E}$ elements. Here, $\mathrm{V}$ elements are referred to as vertices (vertex) or nodes. E elements are expressed as edges. Each edge in E adjoins two different nodes in $\mathrm{Y}$. Nodes are shown by circles and edges are shown by lines (Dharwadker \& Pirzada, 2011). A graph structure with its edges and vertices is shown on Figure 1.

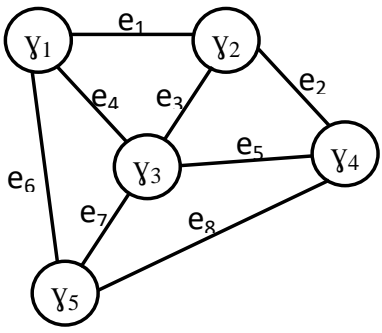

$$
\begin{aligned}
& \mathrm{G}=(\mathrm{V}, \mathrm{E}) \\
& \mathrm{V}=\left\{\mathrm{\gamma}_{1}, \mathrm{\gamma}_{2}, \mathrm{\gamma}_{3}, \mathrm{\gamma}_{4}, \mathrm{\gamma}_{5}\right\} \\
& \mathrm{E}=\left\{\mathrm{e}_{1}, \mathrm{e}_{2}, \mathrm{e}_{3}, \mathrm{e}_{4}, \mathrm{e}_{5}, \mathrm{e}_{6}, \mathrm{e}_{7}, \mathrm{e}_{8}\right\} \\
& \mathrm{e}_{1}=\left(\mathrm{\gamma}_{1}, \mathrm{\gamma}_{2}\right) \quad \mathrm{e}_{2}=\left(\mathrm{\gamma}_{2}, \mathrm{\gamma}_{4}\right) \\
& \mathrm{e}_{3}=\left(\mathrm{\gamma}_{2}, \mathrm{\gamma}_{3}\right) \quad \mathrm{e}_{4}=\left(\mathrm{\gamma}_{1}, \mathrm{\gamma}_{3}\right) \\
& \mathrm{e}_{5}=\left(\mathrm{\gamma}_{3}, \mathrm{\gamma}_{4}\right) \quad \mathrm{e}_{6}=\left(\mathrm{\gamma}_{1}, \mathrm{\gamma}_{5}\right) \\
& \mathrm{e}_{7}=\left(\mathrm{\gamma}_{3}, \mathrm{\gamma}_{5}\right) \quad \mathrm{e}_{8}=\left(\mathrm{\gamma}_{4}, \mathrm{\gamma}_{5}\right)
\end{aligned}
$$

Figure 1. Basic structure of graphs

As shown in Figure 1, this structure also reflects the mesh topology view of computer network structures. As in mesh topology, multiple paths can be defined with different step counts for access between nodes. However, each node is not necessarily directly connected to each other. This depends on the relationships identified in the problem handled. Thus, the graph model can work properly provided that all necessary nodes and inter-node relationships are defined in full.

This study was carried out by focusing on the solution of motion, worker, and mixture problems, $\mathrm{Y}$ and $\mathrm{E}$ on graph structure and the relationships between them. By using the characteristics, variables, operations, types and object relations used in the problems, it is possible to construct a variable-relationship-process tree, i.e. a graph structure. In the scope of this study, the steps taken in the modeling process of the general analyser based on graph structure for solving mathematical problems are shown in Figure 2. 


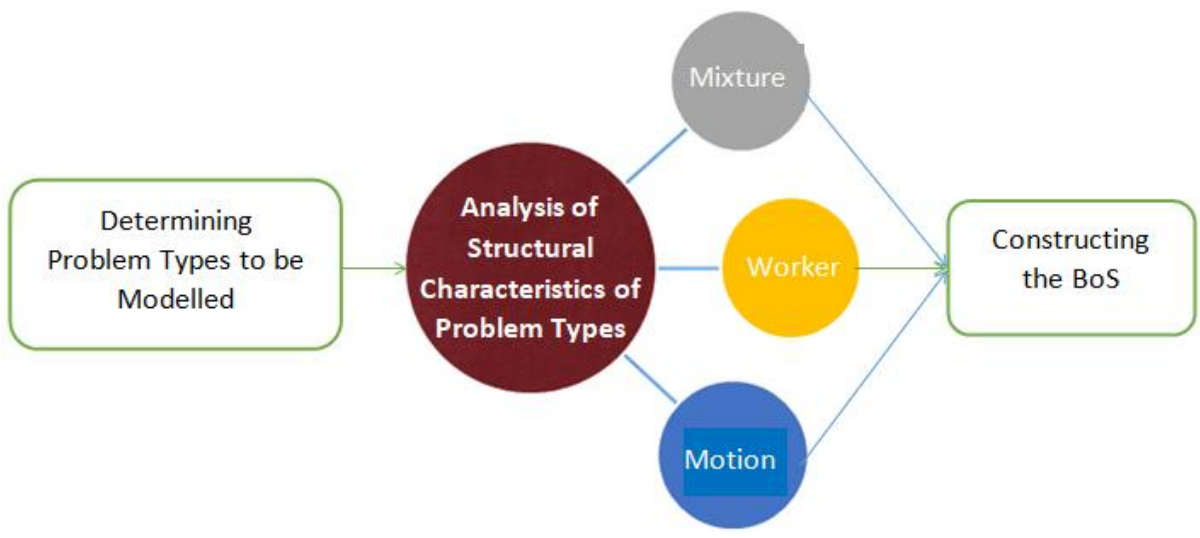

Figure 2. Steps of Development of $B o S$

In order to develop the BoS and to make adjustments by testing both mathematical and algorithmic suitability, a team of 7 experts in mathematics education (a Faculty Member, a PhD Researcher, three PhD students and two postgraduate students), three experts in computer education and instructional technologies (CEIT) (three faculty members), and one expert in computer engineering worked together. First, analyses were done to scrutinize each type of problem under headings such as General Structure, Variables and Definitions, Basic Operations and Types. Then, the problem types were examined together to identify variable relations so that a common graph model could be created. The following section of the study depicts the procedures carried out in this process and the findings step by step.

\subsection{Step 1. Determining Problem Types to be Modelled}

Prior to constructing the BoS, the types of problems to be analyzed were determined. At first, the topics related to mathematical problems in the curricula of many countries were examined. Next, mathematics course books, test books and the questions from the central examinations made in previous years were determined from different countries (Turkey, Germany, Azerbaijan, the UK, and Russia) to select the topics to be included in the study.

In selection of questions for analysing the problem types, a similar path was also followed. Various textbooks, previously asked questions in central exams, and books used extensively were examined. The number of problems analysed for each type of problem and the total number of problems are shown in Table 1.

Table 1. Numbers of Problems Analysed by Type of Problem

\begin{tabular}{llll}
\hline Mixture & Worker & Motion & Total \\
\hline 538 & 493 & 478 & 1509 \\
\hline
\end{tabular}


In this framework, also considering their respective weights in national measurement and placement tests and curriculum; it was decided to study Mixture, Worker and Motion problems following expert opinions.

\subsection{Step 2. Analysis of Structural Characteristics of Types of Problem}

In order to use the graph structure for problem solving, it is necessary to first analyse the problems to reveal their characteristics and basic characteristics in detail. For proper functioning of the $\mathrm{BoS}$, all possible variables for each type of problem (mixture, worker, motion) need identifying and the relationships need uncovering.

\subsubsection{Analysis of Mixture Problems}

Mixture problems are a type of problem in which mixture of solid and liquid substances with each other and the changes occuring thereafter are examined in relation with different indicators.

\section{Overall structure}

In the analysis conducted for this type of problem, problem clusters were formed by classifying the problems in the test books of similar structures. The criterion used for clustering such problems is the number of substances added to the mixture. A total of 538 mixture problems were analysed by mathematics education experts and classified into five types as follows: (1) One-substance mixture, (2) Two or more substance mixtures with given concentration, (3) Adding pure substance, (4) Water evaporation, (5) Subtracting and substituting a substance. Also sub-problem types were identified for each of the categories above. For example; under the heading "adding pure substance", there were found four sub-groups as adding water, adding other substances, adding water and other substances concurrently, and adding water and other substances gradually. Apart from that, the variables necessary for solution of the problems were found as the quantity, unit (gr, kg, liter, ratio), and percentage of the materials used in the mixture and the mixture itself.

\section{Variables and definitions}

In the analysis of mixture problems; it was investigated which substances should be mixed and what characteristics of the mixture are needed in a possible problem. Those characteristics were found as the substance and mixture quantity (m), substance and mixture unit (gram, $\mathrm{kg}$, lt, ratio), substance and mixture percentage $(\% \mathrm{n})$. The information such as percentage, quantity and ratio in Table 2 increases depending on the number of the mixture used in a problem. The expressions and explanations of the characteristics used in this way are shown in Table 2. 
Table 2. Variables in the Mixture and Characteristics

\begin{tabular}{|c|c|c|c|}
\hline Variable & Definition & Variable & Definition \\
\hline $\mathrm{n}$ & Percentage of the mixture & $\mathrm{MKT}_{\mathrm{K}}$ & $\begin{array}{l}\text { The mass of the mixture in the latter } \\
\text { case }\end{array}$ \\
\hline $\mathrm{n}_{\mathrm{T}}$ & $\begin{array}{l}\text { Percentage of the latter } \\
\text { mixture }\end{array}$ & MMT & $\begin{array}{l}\text { Total mass of the substances whose } \\
\text { percentage is given in the latter } \\
\text { mixture }\end{array}$ \\
\hline $\mathrm{mK}_{\mathrm{K}}$ & Mass of the mixture & $\mathrm{R}$ & Ratio of total masses of the mixtures \\
\hline $\mathrm{m}_{\mathrm{m}}$ & $\begin{array}{l}\text { Mass of the substance } \\
\text { whose percentage is given } \\
\text { in the mixture }\end{array}$ & $\mathrm{r}$ & $\begin{array}{l}\text { Ratio of the masses of the } \\
\text { substances in the mixture }\end{array}$ \\
\hline
\end{tabular}

The variables in Table 2 are the basic variables that reflect the information needed when mixture problems are prepared, and they are numbered according to the number of mixtures used in the problem.

\section{Basic operations and types}

In addition to the number of mixtures used in the problem, the operations performed with the mixtures also determine the nature of the problem. The operations performed in mixture problems are basically as follows; combining the mixtures in a separate container, emptying part of the mixture, and evaporating.

The information provided allows creating different groupings and sub-problem types but also preparing the following types of problems under overall mixture problems;

1. Preparing mixture using pure substances (solid-solid, solid-liquid, liquid-liquid),

2. Addition of pure substances in a mixture (solid-solid, solid-liquid, liquid-liquid) into the mixture

3. Addition of a mixture to into another mixture.

An exemplary problem of two-substance mixture along with traditional solution steps are demonstrated in Figure 3. 
Example -1:

Two-Substance Mixture Problem: $25 \mathrm{~kg}$ of a salt-water mixture having a salt content of $16 \%$ and $15 \mathrm{~kg}$ of a salt-water mixture having a salt content of $40 \%$ is mixed. What percentage of the salt content of the new mixture is?

Known:

$n_{1 \mathrm{a}}=\% 16$ (The percentage of salt in first mixture)

$m_{m 1}=25 \mathrm{~kg}$ (The mass of first mixture)

$n_{2 a}=\% 40$ (The percentage of salt in second mixture)

$m_{m 2}=15 \mathrm{~kg}$ (The mass of second mixture)

$p=0$

Solution:
Unknown:

$\mathrm{n}_{\mathrm{Ta}}=$ ? (The percentage of salt in latter mixture)

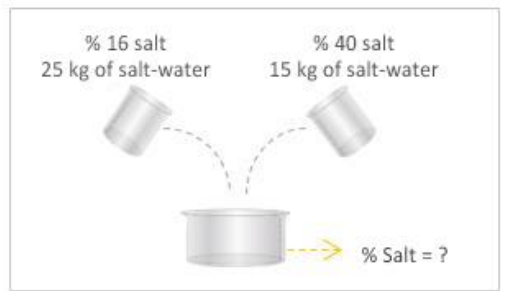

$$
n_{T a}=\left(\frac{n_{1 a} m_{m 1}}{m_{T}}+\frac{n_{2 a} m_{m 2}}{m_{\tau}}\right) \cdot 100=\frac{\frac{16}{100} \cdot 25+\frac{40}{100} \cdot 15}{25+15} \cdot 100=25
$$

Figure 3. Traditional solution steps of a sample two-substance mixture problem

In the problem given in Example 1, $\mathrm{n}_{1 \mathrm{a}}$ stands for the percentage of the first substance in first container and $\mathrm{m}_{\mathrm{K} 1}$ stands for the total mass in this container. In second container, $\mathrm{n}$ and $m_{K}$ variables are known values in the problem. Although the number of containers increases, and the procedures performed vary (evaporation, addition, etc.), the three variables that basically make up mixture problems remain as $n$ (percent of the substance in the mixture), $\mathrm{m}_{\mathrm{K}}$, and $\mathrm{m}_{\mathrm{m}}$. If two of these three variables are given, the other variable can be found. Additionally, it may be necessary to use equations and proportions depending on the nature of the problem.

\section{Analysis of Worker Problems}

Worker problems are a kind of problem in which the parameters included in the process of completion of a work by individuals collectively or individually are examined in relation with different indicators. In order to model worker problems, a comprehensive analysis was first performed on example questions.

\section{Overall structure}

During the analysis, the problems with similar structure in course materials and test books were clustered. So, worker problems were grouped according to the number of workers in the problem. The data necessary for solution of worker problems were found as the time of completion of the work in both cases including individual work or cooperation, or the part of work completed after a certain period of time. 
Variables and definitions

As a result of the analysis, the variables used in worker problems were identified. The variables are given along with definitions in Table 3.

Table 3. Variables of Worker Problems and Definitions

\begin{tabular}{clcl}
\hline Variable & Definition & Variable & Definition \\
\hline $\mathrm{W}$ & The exact ratio of a work $=1$ & $\mathrm{~W}_{\mathrm{U}}$ & $\begin{array}{l}\text { The rate of work completed in unit } \\
\text { amount of time }\end{array}$ \\
\hline $\mathrm{W}_{\mathrm{T}}$ & $\begin{array}{l}\text { Ratio of total work } \\
\text { completed }\end{array}$ & $\mathrm{W}_{\mathrm{t}}$ & $\begin{array}{l}\text { Rate of work completed within } \mathrm{t} \\
\text { period of time }\end{array}$ \\
\hline $\mathrm{W}_{\mathrm{R}}$ & Ratio of remaining work & $\mathrm{t}$ & Period (Time) \\
\hline
\end{tabular}

\section{Basic operations and types}

In general, following common operations were elicited from that kind of problems: the amount of work completed in a given time period if the amount of time taken by a worker to complete a certain amount of work is known; the amount of work completed by two or more workers working together or individually for a certain period of time; working of workers in varying amounts of times; workers quitting or participating in the work; and working of workers at different velocities.

The information provided allows creating different groupings and sub-problem types but also preparing the following types of problems under overall worker problems;

1. Finding the completion period of work by cooperating workers with given information such as time taken by individual workers to finish the work,

2. Finding the completion period of work as a result of working in different periods of time,

3. The amount of work completed by workers by the end of certain periods of time,

4. The completion period of work in case of quitting or participating of workers.

5. Figure 4 depicts the traditional solution of a problem with two workers working for the same amount of time.

Example-2:

Problem With Two Workers: One worker can finish a job in 4 days, and the other worker can finish the same job in 12 days. How many days do two workers finish this job by working together?

Known:

\section{Unknown:}

- $W_{\mathrm{U} 1}=4$

- $W_{\mathrm{U} 2}=12$

- $\mathrm{W}_{\mathrm{T}}=1$

Solution:

$$
\left(\frac{1}{W_{u 1}}+\frac{1}{W_{u 2}}\right) \cdot t=W_{T} \rightarrow\left(\frac{1}{4}+\frac{1}{12}\right) \cdot t=1 \rightarrow t=3 \text { days }
$$

Figure 4. Traditional solution of a problem with two workers 
In the problem given in Example 2, $\mathrm{W}_{\mathrm{U}} 1$ stands for the completion time of a certain amount of work by the first worker, and $\mathrm{W}_{\mathrm{U}} 2$ stands for the completion time of a certain amount of work by the second worker. If the number of workers increases and the types of transactions performed vary (making a certain part of the work, leaving after a certain period of time, etc.), there are three variables $\mathrm{W}_{\mathrm{U}}, \mathrm{W}_{\mathrm{T}}$ and $\mathrm{t}$. If these three variables are given, the third unknown variable can be found. However, equations and ratios may need to be used depending on the nature of the problem. Although the number of workers increases, and the procedures performed vary (completing a certain of the work, quitting the work after a certain period of time, etc.), the three variables that basically make up worker problems remain as $\mathrm{W}_{\mathrm{U}}, \mathrm{W}_{\mathrm{T}}$, and t. Additionally, it may be necessary to use equations and proportions depending on the nature of the problem.

\section{Analysis of Motion Problems}

Motion problems are a type of problem in which the parameters involved in passing a certain distance with a vehicle are examined in relation with different indicators.

\section{Overall structure}

In the analysis conducted for this type of problem, the problems with similar structure in course materials and test books were clustered. So, motion problems were grouped according to the number of vehicles in the problem. The parameters needed for solution of the problems were found as the velocity of the vehicle(s), the total distance to be taken, and the time the vehicle(s) keep in motion. In general, following common operations were elicited from that kind of problems: taking of a distance by a vehicle at a certain velocity in a certain time; moving of two vehicles with a certain distance between them towards each other; and moving of two vehicles with a certain distance between them towards the same direction.

\section{Variables and definitions}

The variables used in motion problems and corresponding definitions are given in Table 4.

Table 4. Variables in Motion Problems and Definitions

\begin{tabular}{ll}
\hline Variable & Definition \\
\hline$\times$ & Distance \\
$\mathrm{V}$ & Velocity \\
$\mathrm{t}$ & Time \\
\hline
\end{tabular}

In general, the formula "Distance $=$ Velocity $\times$ Time" is used in motion problems. The variables in Table 4 refer to the distance taken by the vehicle(s), the velocity of the vehicle(s), and travel times of the vehicle(s). Regardless of the structure of the problem, a motion problem can be established if both of these three variables are given because other variables like the number of vehicles, the geometric shape of the road and so on do not play a key role in solving motion problems. 
Basic operations and types

The principal variable in making motion problems is the number of vehicles. As long as the number of vehicles is determined, motion problems can be prepared on the basis of the variables such as distance to be taken by the vehicle(s), velocities of the vehicle(s), and duration of movement by the vehicle(s).

The information provided allows creating different groupings and sub-problem types but also preparing the following types of problems under overall motion problems;

1. Single-vehicle problems for finding the third variable when any two of velocity, distance and time variables are given,

2. Finding the time of meeting or catching up of two vehicles when they are in motion in the same or opposite directions,

3. Finding the average velocity.

Figure 5 depicts the traditional solution of a problem with two vehicles.

Example 3:

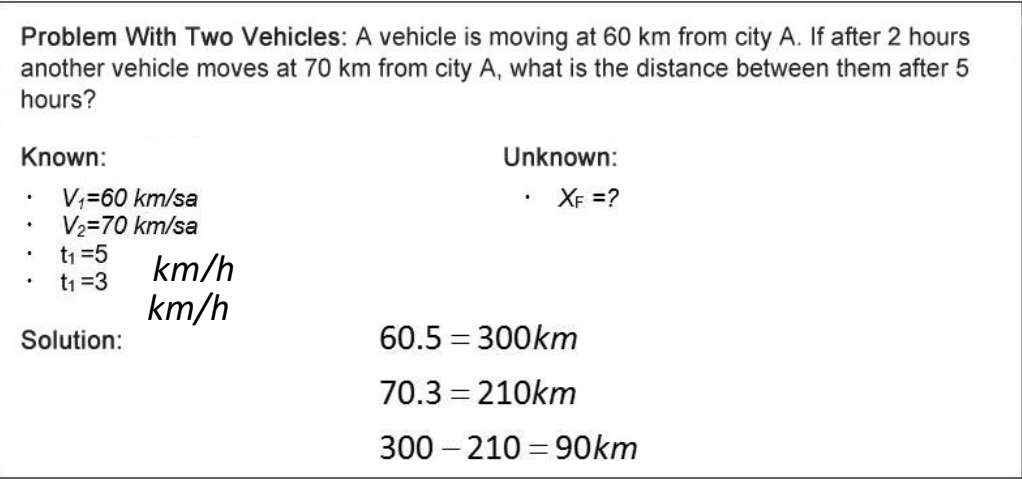

Figure 5. Traditional solution steps of a problem with two vehicles

In the problem given in Example $3, \mathrm{~V}_{1}$ denotes the velocity of the first vehicle and $\mathrm{t}_{1}$ denotes the time that the first vehicle travels. In the second container, variables $\mathrm{V}$ (velocity) and t (time) have a value of 2. Although the number of vehicles increases, and the procedures performed vary (stopping, returning, rotational movement, etc.), the three variables that basically make up motion problems remain as $\mathrm{V}$ (velocity), $\mathrm{t}_{1}$ (first time), and $\mathrm{X}$ (distance). If two of these 3 variables are given, the other variable can be found. Additionally, it may be necessary to use equations and proportions depending on the nature of the problem.

\subsection{Step 3. Constructing the Common Model (BoS) for Types of Problem}

The data obtained from the analysis of the mixture, worker and motion problems were analyzed so as to achieve a common model seeking answer for the question. "Is it possible to combine motion, worker and mixture type problems under a common model (BoS)?" 
With cooperation of three faculty members specialising in computer and instructional technologies and one faculty member specialising in computer engineering a total of 1509 questions were covered for the three types of problems handled in the study and a common model was developed to solve various mixture, worker and motion problems. The common graph model helps find solutions for the variables that make up mixture, worker and motion problems, and various combinations of these variables.

As a result of the analysis on characteristics of mixture, worker and motion problems and solutions performed accordingly, it was understood that problem contents are prepared based on calculation of an unknown (needed) variable by known variables, the graph structure is expanded according to the number of variables, and it is possible to solve problems by using a similar structure. It suggests that although the objects and scenario given in a particular type of problem vary, solution can be achieved through similar graph models. The basic variables used in mixture, worker and motion problems are shown comparatively in Table 5.

Table 5. Variables used in graph model and definitions

\begin{tabular}{llll}
\hline Problem Type & Variables & & \\
\hline \multirow{2}{*}{ Mixture } & $\mathbf{m}_{\mathbf{m}}$ & $\mathbf{m}_{\mathbf{K}}$ & $\mathbf{n}, \mathbf{r}, \mathbf{R}$ \\
& Substance Mass & Mixture Mass & $\begin{array}{l}\text { Substance } \\
\text { Percentage }\end{array}$ \\
& & $\mathbf{T}$ & $\mathbf{W}$ \\
\multirow{2}{*}{ Worker } & Wu & Time & Work ratio \\
& Working capacity & $\mathbf{T}$ & $\mathbf{X}$ \\
\multirow{2}{*}{ Motion } & $\mathbf{V}$ & Time & Distance \\
& Velocity & &
\end{tabular}

It is seen that the problem types have basically three variables and derivatives of these three variables are used in problems. The basic triple variables, symbols and representative graph nodes for the types of problems handled in this study are shown in Table 6.

The basic triple graph structure using the symbols and operation nodes in Table 6 can form the basis for solving mathematical problems. In order to elaborate this proposal, it is necessary to examine a sample problem solution and depiction of the basic triple structure. Figure 6 shows the graph model developed for an example problem solution. 
Table 6. Symbols used in graph model and descriptions

\begin{tabular}{|c|c|c|c|c|c|}
\hline \multirow{2}{*}{ Type } & \multirow{2}{*}{ Basic Triple Variables } & \multirow{2}{*}{ Symbol } & \multicolumn{3}{|c|}{ Status of Node } \\
\hline & & & Known & Unknown & Parametric \\
\hline \multirow{3}{*}{ Mixture } & Substance mass & $\mathrm{m}_{\mathrm{m}}$ & & & \\
\hline & Substance percentage & $\mathrm{n}$ & & & \\
\hline & Total mass of the mixture & $\mathrm{m}_{\mathrm{K}}$ & & & \\
\hline \multirow{3}{*}{ Worker } & $\begin{array}{l}\text { Ratio of total work } \\
\text { completed }\end{array}$ & $\mathrm{W}_{\mathrm{t}}$ & & & \\
\hline & $\begin{array}{l}\text { The rate of work completed } \\
\text { in unit amount of time }\end{array}$ & $\mathrm{W}_{\mathrm{U}}$ & & & \\
\hline & Time & $\mathrm{t}$ & & & \\
\hline \multirow{3}{*}{ Motion } & Distance & $\mathrm{X}$ & & & \\
\hline & Velocity & $\mathrm{V}$ & & & \\
\hline & Time & $\mathrm{t}$ & & & \\
\hline
\end{tabular}

Example-4 (Mixture Problem): How many liters of alcohol is there in 120 liters of alcohol-water mixture with $30 \%$ alcohol content?

Example-5 (Worker Problem): Taylan can do a job in 12 hours, so how much of the job can he do in 4 hours?

Example-6 (Motion Problem): How many kilometers does a car travel in 5 hours when it travels at $90 \mathrm{~km} / \mathrm{h}$ ?

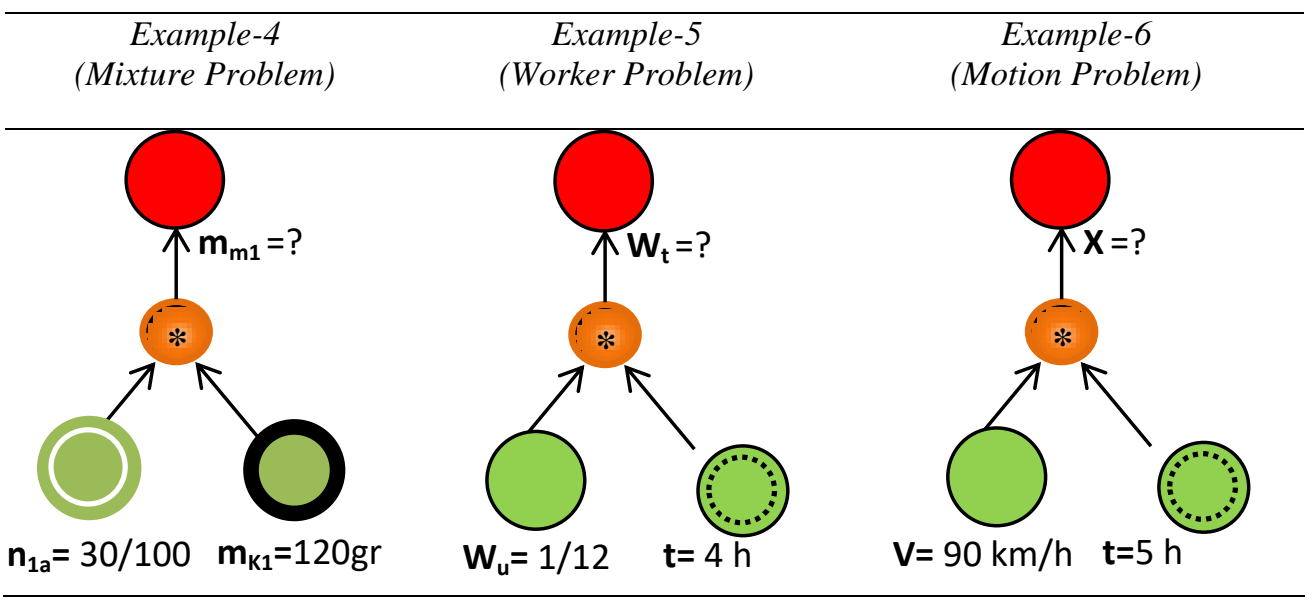

Figure 6. Example of the basic triple graph structure 
Figure 6 shows how to solve three basic types of problems by using the basic triple graph structure containing the main nodes (variables). For example; known values in the mixture problem are the substance ratio and the quantity of mixture. The unknown value is the quantity of alcohol. In the case of the motion and worker problems at the same difficulty level, the known and unknown values are different from the first type. Nevertheless, all the three graph structures are identical except for variable names. The basic graph structure can be expanded to comply with complexity of the content of the mathematical problems (scenario) and number of known variables and parameters.

\section{Running of BoS in Problem Solving Teaching}

In this study, it is described how to use the BoS, the common solution model based on mixture, worker and motion problems, in the context of mathematical problem solving teaching (as seen in Figure 7).

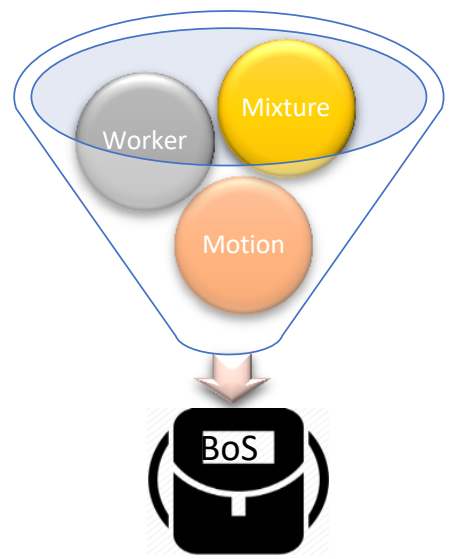

Figure 7. BoS Model

To illustrate appropriateness of the BoS for such a teaching, it would be useful to examine how Graph structures work according to the types of problems.

The solution of the traditionally solved two-substance mixture problem with its modeled graph structure is shown step by step in Figure 8. According to the graph model in Figure 8, once the values given in the problem are placed into the relevant nodes, the solution can be reached by following the numbered steps of operation in correct order. 

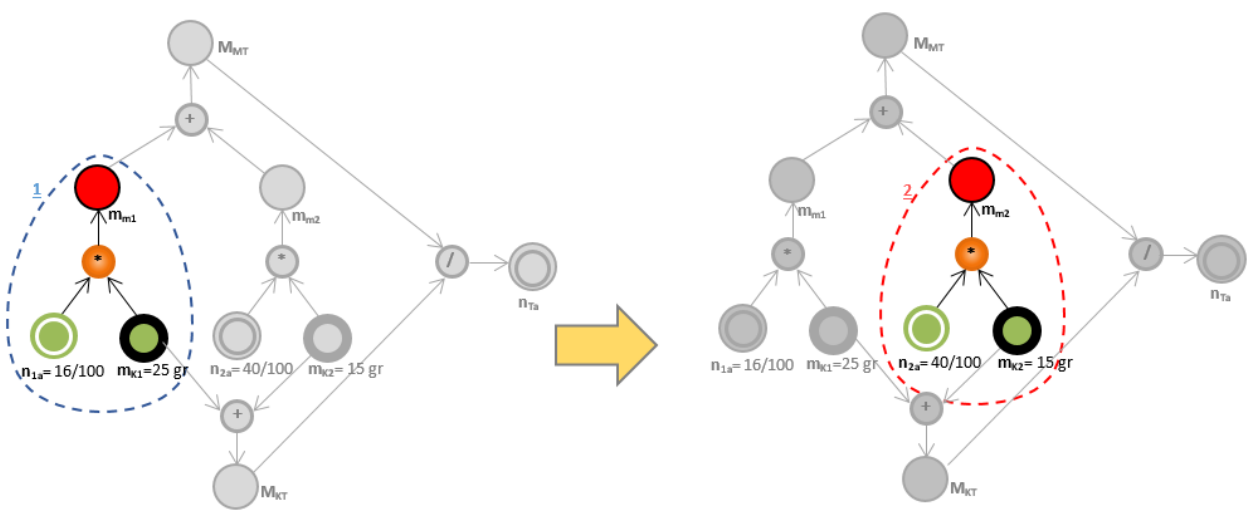

1. $n_{1 a} \cdot m_{K 1}=m_{m 1} \rightarrow \frac{16}{100} \cdot 25=4 g r$

2. $n_{2 a} \cdot m_{K 2}=m_{m 2} \rightarrow \frac{40}{100} \cdot 15=6 g r$
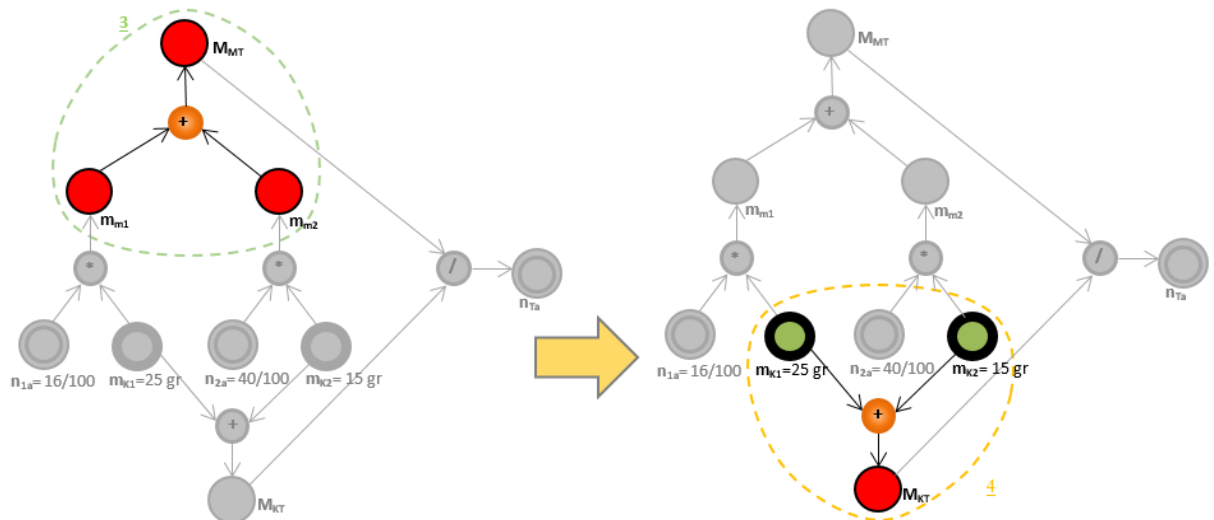

3. $m_{m 1}+m_{m 2}=M_{M T} \rightarrow 4+6=10 g r$

4. $m_{K 1}+m_{K 2}=M_{K T} \rightarrow 25+15=40 g r$ 

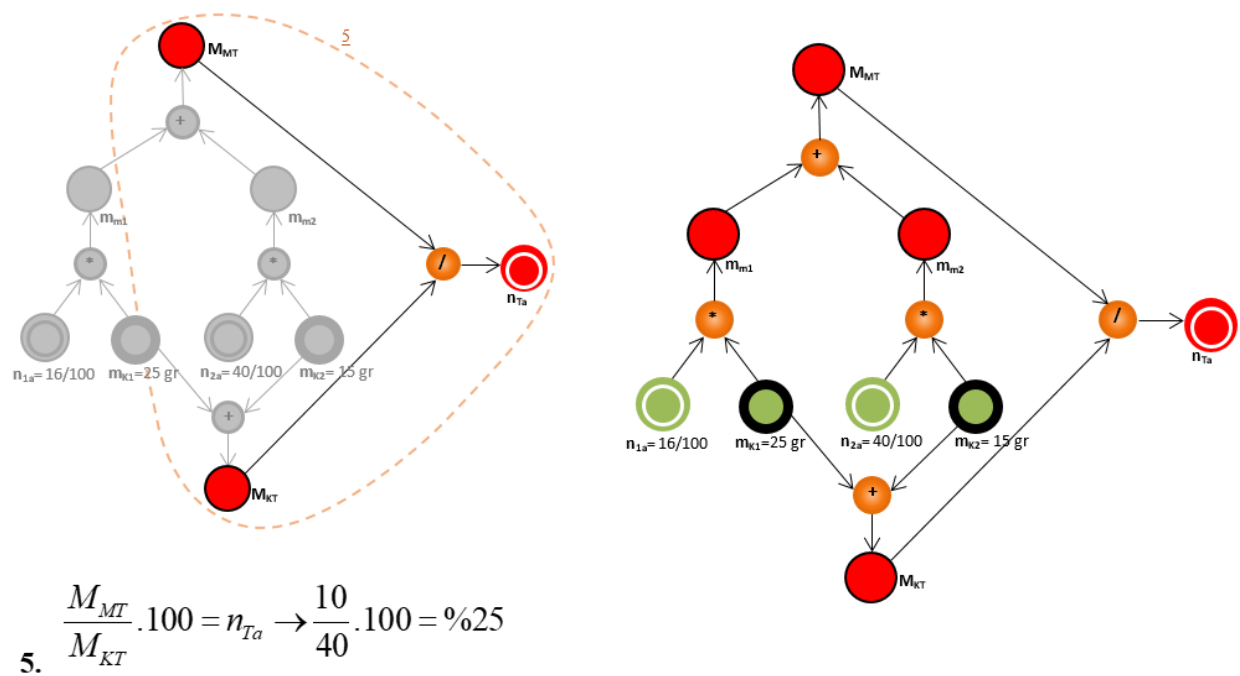

Figure 8. Graph model and solution steps for an example two-substance mixture problem

In the example problem; after the given data (percentage of salt in container 1 $(\mathrm{n} 1 \mathrm{a})=16 \%$, amount of mixture in container $1(\mathrm{mml})=25 \mathrm{~kg}$, percentage of salt in container $2(\mathrm{n} 2 \mathrm{a})=40 \%$, amount of mixture in container $2(\mathrm{~mm} 2)=15 \mathrm{~kg})$ are placed on the graph, pre-determined arithmetic operations are realized in the direction of arrow by going from what is known towards unknown. Every new node value found is checked against the basic triple graph model again to continue finding what is unknown. The procedure is continued till finding what is needed in the problem (salt ratio of the resulting mixture $(\mathrm{nTa})=$ ?). Also possible different solution paths can be discovered by using the relationships between the nodes on the graph.

The 3-dimension basic graph model is also used to for solving worker problems, which have the same structure as mixture problems. The solution and graph model of a two-worker problem with its traditional solution steps is showed in Example-8. The traditional solution steps of the two-substance mixture problem, indicated in Figure 8, are showed with its grafh structure in Figure 9. 


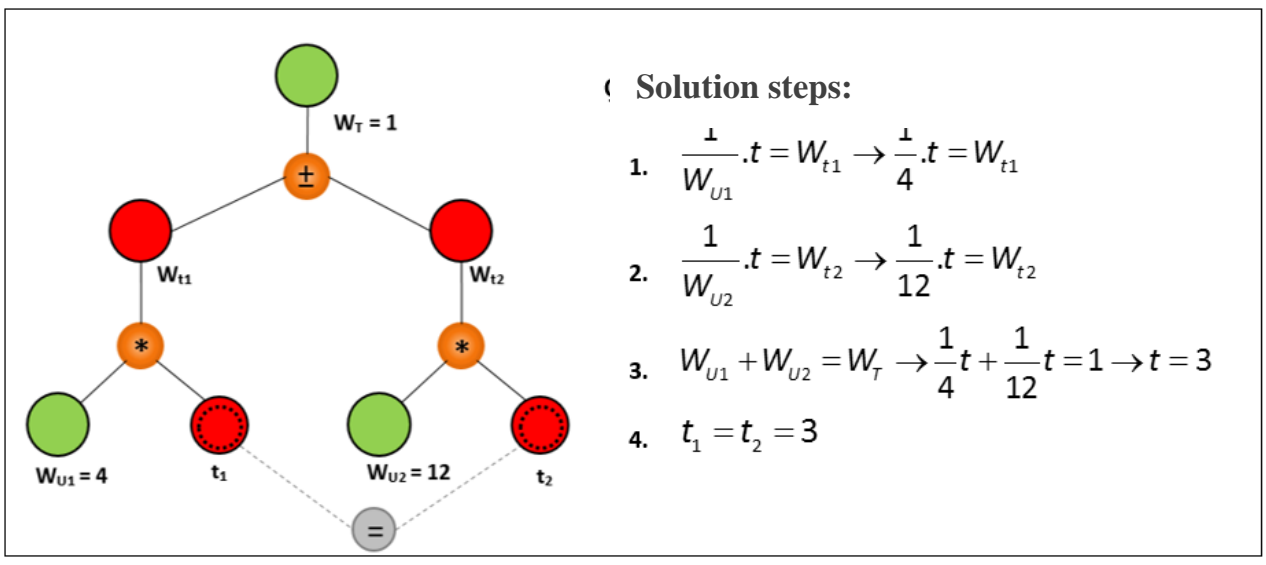

Figure 9. Graph model and solution steps for an example worker problem with two workers

In Example-8, once the given values are located into the relevant nodes on the graph, the solution can be reached by following the numbered steps of operation in correct order.

As in mixture and worker problems, in motion problems, too, the relationship between the three variables from the unknown towards the known is modeled by the same basic triple graph model. Figure 5 shows the traditional solution steps of a problem with two vehicles, while solution steps through the graph structure are displayed in Figure 10.

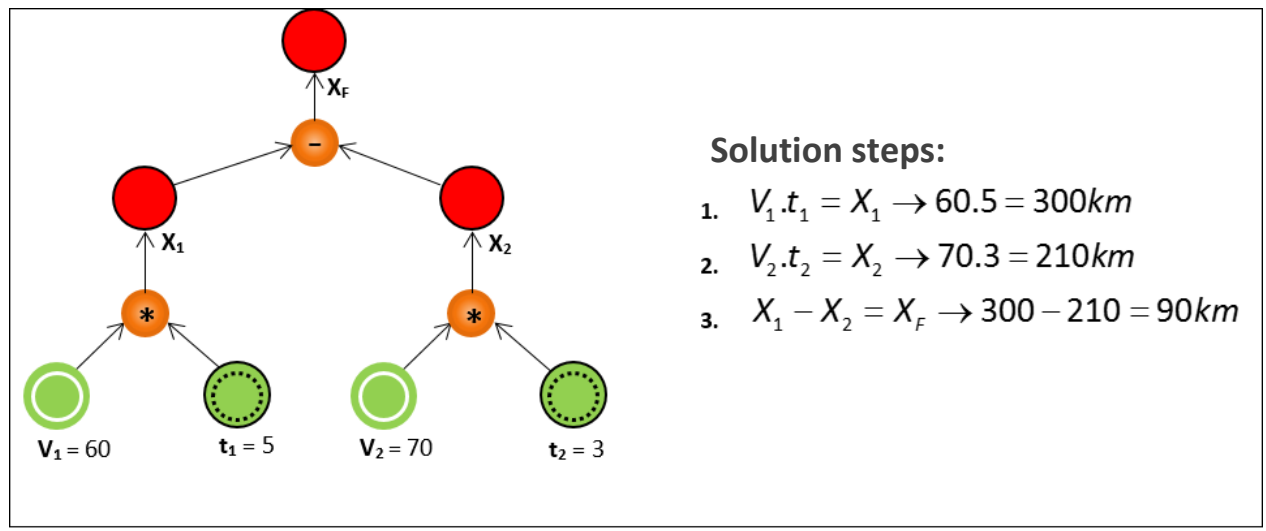

Figure 10. Graph model and solution steps of a motion problem with two vehicles

In the example above; first, the values given are placed in the related nodes on the graph model. Then, the problem is solved by following the steps of operation in the direction from known to unknown. 
The intention of this research is not to explore effects of BoS on students' problem solving and algorithmic thinking skills or on academic achievement. It describes the analyses performed for developing the BoS model and the model itself. The results are given bearing this in mind.

\section{Discussion and Conclusion}

Problem solving is of importance for both mathematics learning and cognitive skills (Schoenfeld, 2017; Sweller et al., 2010). When curricula for K-12 level are examined, topics related to mathematical problems are seen to take place directly in mathematics teaching curriculum in some countries (e.g. Turkey, Azerbaijan, the UK, and Germany), while they take place indirectly in some other countries' curricula (e.g. Japan, Russia, the USA). The importance of mathematical problem solving in terms of mathematics teaching curricula, has led to an increase in the tendency towards this topic and frequent works on this issue (Kilpatrick, 2013).

The review of literature indicates samples about the problem solving process and difficulties faced in this process. However, it is noticed that there are a limited number of studies on solving the difficulties encountered in problem solving, and majority of them are comprised of studies carried out on computer science. Students often try to match the data in the problem with the corresponding formula and can not solve the problem if they can not match the formula. Since an appropriate formula is not available for every single situation encountered in everyday life, it is of great importance to teach students problemsolving logic so that they can produce their own solution paths (Baki, 2008).

At this point, the need for pedagogical use of advanced information and communication technologies rises in the context of problem solving. Actually, it is emphasized in many countries' curricula that timely and effective use of information and communication technologies is important (Beqiri \& Tahiri, 2014), and learners can actively use the software provided for them, construct their mathematical knowledge in accordance with the constructivist approach adopted by the program, resulting in increased success in problem solving (Huang et al., 2012). In this respect, it could be argued that the BoS developed in this research may pose an important infrastructure for probable systems to be developed regarding the problem solving process in the future.

While using computers with an eye to improve problem solving success; first, the problems to be presented to students are analysed to ensure that students deal with problems of different characteristics and to improve their skills to solve those problems (Aqda, Hamidi, \& Rahimi, 2011; Chang et al., 2006; Jacobse \& Harskamp, 2009). To accomplish this, there is a need for software that can support students in the solution process by providing meaningful feedback for the solution done by learners (Arnau, Arevalillo-Herraez, Puig \& Gonzalez-Calero, 2013; Chen, Mdyunus, Ali \& Bakar, 2008). This support, in operational sense, takes place in the form of allowing students to distinguish the given and needed data in the problem, to establish the equation needed for solution, to apply the solution steps, to recognize their mistakes and correct actions, and to try and see different solution paths (Hwang \& Wu, 2012; Mohamedi, Bensebaa \& 
Trigano, 2012). The support provided for learners is quite important in not only operational but also cognitive and motivational senses. The software to be created should increase motivation of learners through feedback (Garcia-Santillan et al., 2012; LopezMorteo \& Lopez, 2007). Such software should be developed in a way not to impose extra cognitive load on learners and confuse them, not to prevent them from focusing on the application, or not to cause them to make more effort to understand the topic (Chen et al., 2008; Jeremic, Jovanovic \& Gasevic, 2012). Programmable and practical qualities of such software have to do with how to model problems with such software as much as the context selected for that. It is not easy for the computer to cover all or most of the problems possible in one context since it cannot think or make decisions like human beings. As a matter of fact, this situation is closely related to the possible sentence structures and the types of problems available in the curriculum (Allahverdi, 2002; Öz \& Baykoç, 2004; Rich, 1983). Thus, it is necessary to develop a model capable of covering all relevant problem types by following a systematic process.

It is known that mathematical modeling becomes increasingly important both in daily life and academic context (English \& Gainsburg, 2016). It is stated that students who understand the concept of mathematical modeling and how it can be used are more successful in solving non-routine problems and real life problems (Dede, 2017; Doruk \& Umay, 2011). Previous research shows that while students are able to learn how to solve a simple routine problem and transfer it to similar problems, they face difficulties in solving problems with higher level of difficulty or non-routine real life problems (Blum, 2011; Xin, Lin, Zhang \& Yan, 2007). In present study, three different types of mathematical problems were investigated based on the graph structure and a general analytical model was developed. Therefore, it is thought to prove that different types of problems (different scenarios, objects and relations between objects) can be solved by using a single model.

The study is a theoretical research on Mathematical problem solving. The BoS as a general analytical model contributes to our understanding of problem solving teaching and provides opportunity to solve different types of problems using a single model. It is expected that the BoS, which is the outcome of this study, will not only provide an algorithmic basis for developing computer-aided instructional materials, adaptive systems and intelligent instructional systems in relation to problem solving but also help students develop a new understanding of the problem-solving process. A common graph structure that can cover the entirety of a specific type of problem can allow students to construct their own learning while they are solving the problem step by step. Consequently, it could be possible to achieve a learning experience in which the process gains importance and the logic of analysis is taught through computers replacing template-based teaching which requires memorization of already-known formulas for finding the result only.

The literature provides only a very limited number of studies conducted to analyze mathematical problems using graph structure. In his study, Smithers (2005) focused on teaching of graph theory to junior high school students as a part of mathematics education. As a result of the study, he stated that graph theory in mathematical modeling can be used effectively. In such a research study, Sümersan-Seyhanl1 (2007) has focused on the use of graph theory by the teacher in teaching probability subject. In this study, the teacher has 
benefited from the visual representation of probability problems (representation of all the possibilities in the tree structure) in order that students could better understand the problems. In this way, students have been able to find easily the solution identifying the known and the unknown data in the problems. Students who worked the subject of probability with graph theory have outperformed than those who processed traditionally. In a study conducted by Erümit, Karal and Nabiyev (2012), a computerized solution model based on graph structure was developed for non-parametric motion problems. In above mentioned study, 250 motion problems were analyzed with the solution model based on the graph structure developed. The studies in question reveal that only one single type of problem can be modeled but a common graph structure is not established for mathematical problems involving different types and scenarios. Hence, the BoS general analysing model obtained in our study is thought to be significant as it shows that the solutions of mathematical problems can be modeled by a common structure.

As a result, an important implication regarding the authentic quality of this study is that a systematic approach to modeling solution of different types of mathematical problems was followed yielding the BoS with an interdisciplinary point of view. In this regard, effective use of graph theory, which is extensively used in computer sciences area, in the pedagogical context and the steps of model development can shed light on the theoretical and practical aspects of future works. Moreover, it can be said that the resulting BoS model can be used as an important input for teaching systems and online learning environments oriented to problem solving.

\section{Limitations and Suggestions}

As the BoS is employed for problem-solving teaching, it is suggested to teach that different types of problems for which separate formulas are provided and are structurally the same indeed. This can be inferred from a structure in which students try to solve problems by learning by heart the formulas that fit only with certain patterns. Instead of contemplating and memorizing the structure of problems, students can learn how to solve them step by step algorithmically. Replacing the formulas traditionally given as a means of expressing the structure of problem types in mathematics curricula with BoS can also lead to changes in the problem-solving instruction in schools.

The study developed a common model for solution of only three types of problems namely Mixture, Worker and Motion. In future studies, the scope of the general analytical model based on the graph structure can be expanded by taking into consideration other types of mathematical problems. Also faculty members of mathematics education can be asked for their views about our model to make inferences on how to employ it in the real learning environment. Furthermore, adaptive intelligent teaching systems can be developed for solving mathematical problems based on the existing general analytical model, and mathematical problem solving experiences of students during the learning process can be monitored and reported. Last but not the least, once the general analytical model based on the graph structure is put into use as a part of face-to-face teaching process, further studies could be carried out to improve problem-solving skills of students. 


\section{References}

Allahverdi, N. (2002). Expert systems: The artificial intelligence application. Ankara: Atlas Publishing.

Aqda, M. F., Hamidi, F., \& Rahimi, M. (2011). The comparative effect of computeraided instruction and traditional teaching on student's creativity in math classes. Procedia Computer Science, 3, 266-270.

Anzelmo-Skelton, N. (2006). Learning style, strategy use, personalization of mathematical word problems and responses of students with learning disabilities. International Journal of Special Education, 21(1), 1-10.

Arnau, D., Arevalillo-Herraez, M., Puig, L., \& Gonzalez-Calero, J. A. (2013). Fundamentals of the design and the operation of an intelligent tutoring system for the learning of the arithmetical and algebraic way of solving word problems. Computers \& Education, 63, 119-130.

Baki, A. (2008). Kuramdan uygulamaya matematik eğitimi. Ankara: Harf Eğitim Yayıncilik.

Ben-Hur, M. (2006). Concept-rich mathematics instruction: Building a strong foundation for reasoning and problem solving. Alexandria, VA.: Association for Supervision and Curriculum Development.

Beqiri, E., \& Tahiri, M. (2014). An effective use of information and communication technology in education systems of countries in south-east europe. Academic Journal of Interdisciplinary Studies, 3(2), 91-102.

Berry, J., \& Houston, K. (1995). Mathematical modelling. Bristol: J. W. Arrowsmith Ltd.

Blatchford, P., Bassett, P., \& Brown, P. (2011). Examining the effect of class size on classroom engagement and teacher-pupil interaction: Differences in relation to pupil prior attainment and primary vs. secondary schools. Learning and Instruction, 21(6), 715-730.

Blum, W. (2011). Can modeling be taught and learnt? Some answers from empirical research. In G. Kaiser, W. Blum, R. BorromeoFerri, \& G. Stillman (Eds.), Trends in teachingand learning of mathematical modeling (pp. 15-30). New York: Springer.

Cai, J. (2003). Singaporean students mathematical thinking in problem solving and problem posing: An exploratory study. International Journal of Mathematical Education in Science and Technology, 34(5), 719-737.

Chang, K. E., Sung, Y. T., \& Lin, S. F. (2006). Computer-assisted learning for mathematical problem solving. Computers \& Education, 46, 140-151.

Chen, T., Mdyunus, A., Ali, W. Z. W., \& Bakar, A. (2008). Utilization of intelligent tutoring system in mathematics learning. International Journal of Education and Development Using Information and Communication Technology, 4(4), 50-63.

Chingos, M. M. (2012). The impact of a universal class-size reduction policy: Evidence from Florida's statewide mandate. Economics of Education Review, 31, 543-562.

Chiu, M. M., \& Klassen R. M. (2010). Relations of mathematics self-concept and its calibration with mathematics achievement: Cultural differences among fifteenyear olds in 34 countries. Learning and Instruction, 20(1), 2-17. 
Cho, H., Glewwe, P., \& Whitler, M. (2012). Do reductions in class size raise students' test scores? Evidence from population variation in Minnesota's elementary schools. Economics of Education Review, 31, 77-95.

Crippen, J. K., \& Earl, B. Y. (2007). The impact of web-based worked examples and selfexplanation on performance, problem solving, and self-efficacy. Computers \& Education, 49, 809-821.

Çelik, D., \& Güler, M. (2013). Examination of realistic problem solving skills of sixth grade students. Dicle University Ziya Gökalp Education Faculty Journal, 20, 180-195.

De Corte, E., \& Masui, C. (2004). The CLIA-model: A framework for designing powerful leaming environments for thinking and problem solving. European Journal of Psychology of Education, 19(4), 365-384.

Dede, A. T. (2017). Examination of the relationship between modelling competencies and class level and mathematics achievement. Elementary Education Online, 16(3), 12011219.

Dharwadker, A., \& Pirzada, S. (2011). Graph theory. India: Amazon.

Doruk, B. K., \& Umay, A. (2011). The effect of mathematical modeling on transferring mathematics into daily life. Hacettepe University Journal of Education, 41(41), 124135.

Elia, I., van den Heuvel-Panhuizen, M., \& Kolovou, A. (2009). Exploring strategy use and strategy flexibility in non-routine problem solving by primary school high achievers in mathematics. ZDM Mathematics Education, 41, 605-618.

English, L. D., \& Gainsburg, J. (2016). Problem solving in a 21st century mathematics curriculum. In L. D. English, \& D. Kirshner (Eds.), Handbook of international research in mathematics education (pp. 313-335, 3rd ed.). New York: Taylor and Francis.

Erdem, Z. Ç., Doğan, M. F., Gürbüz, R., \& Şahin, S. (2017). The reflections of mathematical modeling in teaching tools: Textbook analysis. Adlyaman University Education Sciences Journal, 7(1), 61-86.

Erdoğan, A. (2015). Turkish primary school students' strategies in solving a non-routine mathematical problem and some implications for the curriculum design and implementation. International Journal for Mathematics Teaching and Learning, 2, 127.

Erümit, K., Karal, H., \& Nabiyev, V. (2012). Proposing a model for computed analyzing of the motion problems without parameter. Education Sciences, 7(2), 565-573.

Garcia-Santillán, A., Flores-Zambada, V., Escalera-Chávez, M. E., Chong-González, I. S., \& Lopez-Morales, J. S. (2012). Students, computers and mathematics: How do they interact in the teaching-learning process? (An empirical study on accounting, management and marketing undergraduate students). International Journal of Learning \& Development, 2(2), 178-200.

Gooding, S. (2009). Children's difficulties with mathematical word problems. Proceedings of the British Society for Research into Learning Mathematics, 29(3), 3136. 
Hoffman, B., \& Spatariu, A. (2008). The influence of self-efficacy and metacognitive prompting on math problem-solving efficiency. Contemporary Educational Psychology, 33, 875-893.

Huang, T. H., Liu, Y. C., \& Chang, H. C. (2012). Learning achievement in solving wordbased mathematical questions through a computer-assisted learning system. Educational Technology \& Society, 15(1), 248-259.

Hwang, G. J., \& Wu, P. H. (2012). Advancements and trends in digital game-based learning research: A review of publications in selected journals from 2001 to 2010. British Journal of Educational Technology, 43(1), E6-E10. doi: 10.1111/j.14678535.2011.01242.x

Jacobse, A. E., \& Harskamp, E. G. (2009). Student-controlled metacognitive training for solving word problems in primary school mathematics. Educational Research and Evaluation, 15(5), 447-463.

Jeremic, Z., Jovanovic, J., \& Gasevic, D. (2012). Student modeling and assessment in intelligent tutoring of software patterns. Expert Systems with Application, 39, 210-222.

Jonassen, D. H. (2011). Learning to solve problems: A handbook for designing problem solving learning environments. New York: Routledge.

Kaiser, G., \& Schwarz, B. (2006). Mathematical modeling as bridge between school and university. Zentralblattfür Didaktik der Mathematik-ZDM, 38, 196-208.

Kilpatrick, J. (2013). A retrospective account of the past 25 years of research on teaching mathematical problem solving. E. A. Silver (Ed.), Teaching and learning mathematical problem solving: Multiple research perspectives (pp. 1-15). New York: Routledge.

Lesh, R. A., \& Doerr, H. M. (2003). Beyond constructivism: Models and modeling perspectives on mathematics problem solving, learning, and teaching. New Jersey: Routledge.

Li, Q., \& Ma, X. (2010). A meta-analysis of the effects of computer technology on school students' mathematics learning. Educational Psychology Review, 22(3), 215-244.

Lopez-Morteo, G., \& López, G. (2007). Computer support for learning mathematics: A learning environment based on recreational learning objects. Computers \& Education, 48(4), 618-641.

Mohamedi, H., Bensebaa, T., \& Trigano, P. (2012). Developing adaptive intelligent tutoring system based on item response theory and metrics. International Journal of Advanced Science and Technology, 43, 1-14.

Nabiyev, V. V. (2012). Yapay zeka (5th ed.). Ankara: Seçkin Yayıncılık.

Olkun, S., Şahin, Ö., Akkurt, Z., Dikkartin, F. T., \& Gülbağc1, H. (2009). Problem solving and generalization through modeling: A study on elementary school students. Education and Science, 34(151), 65-73.

Öz, E., \& Baykoç, O. F. (2004). Decision theory supported expert system approach to supplier selection problem. Gazi Üniversitesi Mühendislik-Mimarlık Fakültesi Dergisi, 19(3), 275-286.

Polya, G. (1957). How to solve It. New Jersey: Princeton University.

Popper, K. R. (1999). All life is problem solving (P. Carmiller, Trans.). London: Routledge. 
Rich, E. (1983). Artificial intelligence. The University of Texas at Austin: McGraw-Hill Inc.

Singh, P., \& Lokotsch, K. (2005). Effects of transformational leadership on human resource management in primary schools. South African Journal of Education, 25(4), 279-286.

Skemp, R. (1986). The psychology of mathematics learning. Suffolk: Penguin Books.

Smithers, D. B. (2005). Graph theory for the secondary school classroom (Unpublished doctoral dissertation). East Tennessee State University, Johnson City.

Schoenfeld, A. H. (2017). Learning to think mathematically: Problem solving, metacognition, and sense making in mathematics. Journal of Education, 196(2), 1-38.

Soylu, Y., \& Soylu, C. (2006). The role of problem solving in mathematics lessons for success. Journal of Inönü University Faculty of Education, 7(11), 97-111.

Sümersan-Seyhanl1, S. (2007). The effect on the student achievement of graph theory in teaching of the unit of "probability" of primary school 8th (Unpusblished master's thesis). Balıkesir University, Balıkesir.

Sweller, J., Clark, R., \& Kirschner, P. (2010). Teaching general problem-solving skills is not a substitute for, or a viable addition to, teaching mathematics. Notices of the American Mathematical Society, 57(10), 1303-1304.

Thomas, J. L. (2012). Combination classes and educational achievement. Economics of Education Review, 31, 1058-1066.

Vicente, S., Orrantia, J., \& Verschaffel, L. (2007). Influence of situational and conceptual rewording on word problem solving. British Journal of Educational Psychology, 77(4), 829-848.

Xin, Z., Lin, C., Zhang, L., \& Yan, R. (2007). The performance of Chinese primary school students on realistic arithmetic word problems. Educational Psychology in Practice, 23, 145-159.

Yavuz-Mumcu, H., \& Baki, A. (2017). The interpretation of mathematical modelling skills of high school students in the activities of using mathematics. Ondokuz Mayls University Journal of Faculty of Education, 36(1), 7-33.

Yen, J. C., \& Chen, M. P. (2008). Patterns of reflection for problem-solving in a mobile learning environment. International Journal of Education and Information Technologies, 2(2), 121-124. 